\title{
Perceived Vulnerability to Disease Questionnaire: Psychometric Validation with a Portuguese Sample
}

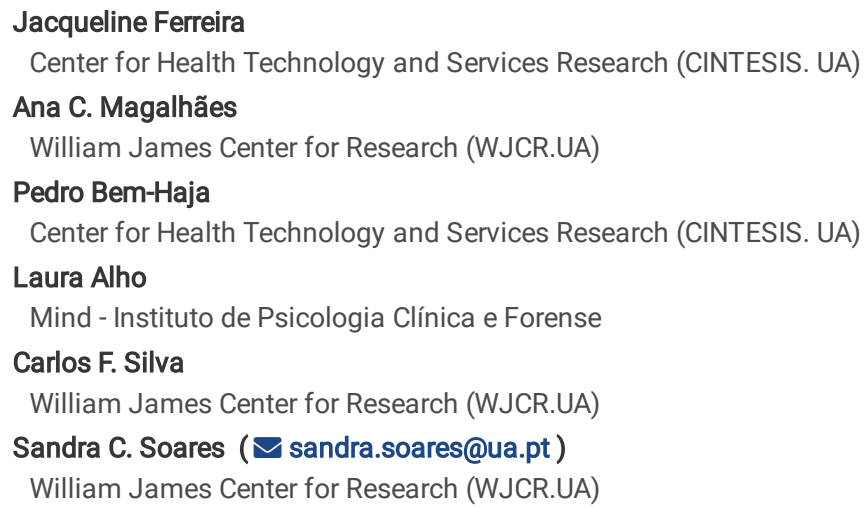

Keywords: Perceived Vulnerability to Disease, Disease Avoidance, Perceived Infectability, Germ Aversion, Individual Differences

Posted Date: December 9th, 2021

DOI: https://doi.org/10.21203/rs.3.rs-1123800/v1

License: () (7) This work is licensed under a Creative Commons Attribution 4.0 International License. Read Full License 


\section{Abstract \\ Background}

Individual differences in one's perceived vulnerability to disease are implicated in psychological distress, social and behavioral disease avoidance phenomena. The Perceived Vulnerability to Disease Questionnaire (PVD) is the most extensively used measure when it comes to assessing subjective vulnerability to infectious diseases. However, this measure is not yet accessible to the Portuguese population. The present study examined the psychometric properties of the PVD with 136 Portuguese participants.

\section{Methods}

Factorial, convergent and discriminant validity (of both the scale and between each factor), and reliability analysis were assessed.

\section{Results}

A modified bifactorial model, comprised of Perceived Infectability and Germ Aversion factors, was obtained, with acceptable goodness-of-fit indices, adequate convergent and discriminant validity, and good internal consistencies.

\section{Conclusions}

Overall, the 10-items European-Portuguese PVD appears to be a reliable and valid measure of one's perceived vulnerability to disease, with potential relevance for application in both research and clinical practice pertaining to disease-avoidance processes.

\section{Background}

Humans, like other animals, possess specialized systems that protect them from pathogens, which pose high risks for the survival and reproductive fitness of the species $(1,2)$. One of these systems is the biological immune system, responsible for detecting and destroying foreign elements once they enter the body. However, this complex set of responses is merely reactive, occurring only after an infection has settled, and entails some constraints for the individual, namely the high consumption of physiological energy and the loss of social opportunities (e.g., forming friendship/romantic relationships) $(3,4)$. Thus, having a system capable of avoiding pathogens before they enter the body would reduce such costs.

The behavioral immune system (BIS) provides an early defensive response against pathogens. It is extremely sensitive to any cues (be it in objects or people) that suggest the presence of disease in the environment, even if they do not represent a real risk of contagion $(5,6)$. Once detected, these cues trigger a disgust reaction, cognitive biases and behavioral avoidance responses with the ultimate goal of inhibiting contact with pathogens (4).

The intensity of these responses is influenced not only by the salience of disease cues, but also by individual differences. For instance, Mortensen and colleagues (7) showed that a high disease salience (disease versus neutral prime) can temporarily influence individual's personality traits by making them perceive themselves as less extroverted and open to experience. These traits reflect less willingness to engage in social interactions, a response closely linked to the BIS. Moreover, these effects were more prominent in individuals who perceived themselves as more vulnerable to disease. This is in line with one assumption of the BIS, which states that individuals who are - or merely perceive themselves to be - more vulnerable to infection, display stronger aversive responses towards pathogen-connoting stimuli (5).

Different types of self-report instruments used to assess perceived vulnerability to disease exist, but only one reliably measures individual differences in perceived vulnerability to infectious diseases. First, measures of disgust sensitivity, but these tend to focus on a broad range of stimuli of which only a subset are directly relevant to disease transmission. Second, instruments designed to assess hypochondria and other health-relevant anxieties. However, these involve several potential health problems, not only infectious diseases (8). The Perceived Vulnerability to Disease questionnaire (PVD) is widely used and was first introduced by Park and colleagues (9). Throughout the years, it underwent multiple revisions (14 to 19 items) until Duncan and collaborators (8) developed and validated a 15-item version of the scale, which assesses one's beliefs about personal susceptibility to and emotional discomfort associated with a potential contagion from infectious diseases. This version has shown good psychometric properties and can be used with the general population.

Studies using the PVD have been consistently showing that individuals chronically concerned about disease transmission seem to be more sensitive to cues heuristically associated with disease and, consequently, tend to adopt more overt discriminant behaviors towards others perceived as having a poor health status, like the obese, the elderly or people with physical disabilities (9-11). They also tend to show more ethnocentric and xenophobic attitudes against strangers $(12,13)$. Thus, despite the protective role of the BIS, it also seems to contribute to aversive responses towards people associated with a risk for contagion $(2,3)$. Furthermore, while perceived vulnerability to disease leads people to engage more fully in proactive preventative behaviors, especially beneficial when the risk of contagion is high (e.g., Covid-19 pandemic), it has also been associated with considerable psychological distress, increasing both anxiety and depression levels $(14,15)$. However, no instrument to measure the perceived vulnerability to infectious diseases exists for the Portuguese population.

Understanding how this variable contributes to the inhibition of social interactions can be helpful for the development of better social strategies aimed at dealing with negative behaviors against people who are (or appear to be) ill, and with the increased psychological distress felt by those who regard themselves as more susceptible to diseases. Thus, the main goal of this study was to analyze the psychometric properties of the PVD for the Portuguese population.

Page 2/12 


\section{Methods}

\section{Participants}

One-hundred ninety-five participants, aged between 18 and 65 years ( 155 women, $M=26.16, S D=8.86$ ) from three Portuguese Universities voluntarily filled the online protocol. Fifty-nine were excluded because they did not fully complete it. The final sample included 136 participants $(109$ women, $M=27.01, S D=$ 9.77).

\section{Instruments}

The Perceived Vulnerability to Disease Questionnaire (PVD; 8), a 15-item seven-points scale (1 = "Strongly Disagree" to 7 = "Strongly Agree") with two factors, "Perceived Infectability" (PI) and "Germ Aversion" (GA), was completed.

Participants also completed the Disgust Propensity and Sensitivity Scale-Revised (DPSS-R; 16),a11-item five-points scale divided into two subscales: "Disgust Propensity" and "Disgust Sensitivity"; the Disgust Scale-Revised (DS-R; 17), a 27-item five-points scale measuring disgust in three dimensions: "Core Disgust", "Animal-reminder Disgust" and "Contamination-based Disgust"; the Maudsley Obsessive Compulsive Inventory (MOCl; 18), with 30 true/false items measuring obsessive-compulsive symptoms in three subscales: "Doubting and Rumination", "Checking" and "Cleaning"; the Spider Phobia Questionnaire-Revised (SPQR15; 19), with 15 true/false items measuring fear and avoidance of spiders; the Minnesota Multiphasic Personality Inventory-2 Hypochondria subscale (MMPI-2 Hs; 20), with true/false items assessing hypochondria symptoms and physical well-being; and the NEO-Five Factor Inventory (NEO-FFI; 21), a 60 yes/no measure assessing Neuroticism, Extraversion, Openness, Agreeableness and Conscientiousness.

\section{Procedure}

The PVD was adapted to Portuguese using the translation/back-translation methodology (22). First, it was translated into European-Portuguese by two bilingual individuals and reviewed by a highly proficient in English researcher. Afterwards, it was submitted to a think-aloud procedure, back-translated by a bilingual researcher and sent to the original authors for final approval of the Portuguese version.

The entire protocol was available online. The access link was sent to three Universities and divulged through their staff/student mailing lists. All participants were asked to read the instructions, provide informed consent and fill out the scales and sociodemographic information.

\section{Statistical Analysis}

All analysis were performed using R (23). The following packages were used: highr (24), rio (25), psych (26), GPArotation (27), EFAtools (28), readxl (29) and lavaan (30).

Mardia's Test was performed to assess multivariate normality of the sample (31) and the Jöreskog and Sörbom (32, p.171) equation (see below) to verify the adequacy of the sample size for the factor analysis.

$$
\text { Number of Participants }=\frac{(p+1)(p+2)}{2}
$$

where $p$ is the number of observed variables.

Construct validity was evaluated by calculating its three sub-components: Factorial, convergent and discriminant validity. Since versions from different countries show inconsistent factorial structures, an Exploratory Factor Analysis (EFA) followed by a Confirmatory Factor Analysis (CFA) using weighted leastsquare-mean and variance adjusted estimator (WLSMV) were conducted. Several CFAs were compared to verify the factor structure that best fits the data. The overall goodness-of-fit was assessed using the following indexes and cut-off points for "good adjustment": Chi-square (X2); Comparative Fit Index (CFl; .90 $\leq$

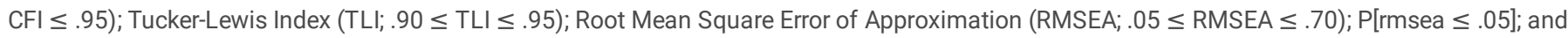
Standardized Root-Mean-Residual (SRMR; SRMR < .80) (33).

Convergent and discriminant validity between the two PVD factors, and of the scale, were assessed using the Fornell and Larcker (34) method and the correlational method, respectively. Thus, to show convergent validity, positive and significant Spearman correlations between PVD factors and both DPSSR subscales, DS-R (total score, Core Disgust and Contamination-based Disgust subscales), MOCl, MMPI-2 Hs and NEO-FFI Neuroticism were expected. Particularly, a stronger correlation between GA and disgust propensity (i.e., DPSS-R Disgust Propensity, and DS-R subscales, especially Contamination-based Disgust), GA and $\mathrm{MOCl}$, and PI and MMPI-Hs were expected. Conversely, discriminant validity was expected to result in low or non-significant correlations between PVD factors and DS-R Animal-reminder Disgust subscale, SPQ-R15 and NEO-FFI subscales (except Neuroticism).

Considering the ordinal nature of the data, a reliability analysis using Ordinal Cronbach's alpha, based on polychoric correlation, was performed to test the internal consistency of the factors.

\section{Results}

Mardia's test showed that data is not multivariate normal, $g 1 p=34.23, \chi$ Skew $=1243.78, p<.001 ; g 2 p=281.09$, ZKurtosis $=8.53, p<.001 ; \chi S M S k e w=$ $1263.08, p<.001$. Sample size was considered adequate for factorial analysis. 
Bartlett's test of sphericity was significant, $\chi^{2}(105)=599.93, \mathrm{p}<.001$, and the Kaiser-Meyer-Olkin Measure of Sampling Adequacy (KMO) analysis returned a value of .81 for the overall matrix, and values between .65 and .96 for all variables. Both indicators support factor analysis as a useful approach to the data.

Parallel analysis with unweighted least-squares estimator (ULS) indicated that three factors should be retained (see Figure 1). However, only two principal factor eigenvalues reached values greater than 1 or .7 (old and new Keiser Criterion, respectively). Moreover, Hull method with CFI and RMSEA, and lower bound of RMSEA $90 \% \mathrm{Cl}$, also support a two-factor retention. Given these results and the conceptual framework surrounding the bifactorial structure of the original scale, a two-factor solution was extracted.

An EFA with Promax rotation using ULS estimator was performed. Factor loadings and respective $\mathrm{R}^{2}$, Uniqueness and Complexity by factor are shown in Table 1.

\begin{tabular}{|c|c|c|c|c|c|c|}
\hline & \multicolumn{6}{|l|}{ Factor } \\
\hline & $\mathrm{F} 1(\mathrm{PI})$ & F2(GA) & $\mathrm{R}^{2}$ & Uniqueness & Complexity & CL Ratio \\
\hline Q1 & -0.09 & 0.68 & 0.43 & 0.57 & 1.0 & 7.6 \\
\hline Q2 & $0.43^{\mathrm{LL}}$ & 0.31 & 0.38 & 0.62 & 1.8 & $1.4^{\mathrm{CL}}$ \\
\hline Q3 & -0.15 & 0.57 & 0.29 & 0.71 & 1.1 & 3.8 \\
\hline Q4 & 0.01 & 0.60 & 0.37 & 0.63 & 1.0 & 60 \\
\hline$\underline{Q} \underline{5}$ & 0.55 & -0.30 & 0.28 & 0.72 & 1.6 & $1.8^{\mathrm{CL}}$ \\
\hline$\underline{Q} \underline{6}$ & $0.44^{\mathrm{L}}$ & 0.04 & 0.21 & 0.79 & 1.0 & 11 \\
\hline Q7 & 0.01 & 0.68 & 0.47 & 0.53 & 1.0 & 68 \\
\hline Q8 & 0.84 & -0.13 & 0.64 & 0.36 & 1.1 & 6.5 \\
\hline$Q \underline{9}$ & 0.01 & $0.41^{\mathrm{L}}$ & 0.17 & 0.83 & 1.0 & 41 \\
\hline Q10 & 0.58 & 0.22 & 0.47 & 0.53 & 1.3 & 2.6 \\
\hline Q11 & 0.00 & 0.57 & 0.33 & 0.67 & 1.0 & 57 \\
\hline Q12 & 0.70 & 0.01 & 0.49 & 0.51 & 1.0 & 70 \\
\hline Q13 & 0.19 & $0.38^{L L}$ & 0.23 & 0.77 & 1.5 & $2^{\mathrm{CL}}$ \\
\hline Q14 & 0.59 & 0.07 & 0.38 & 0.62 & 1.0 & 8.4 \\
\hline Q15 & 0.05 & 0.59 & 0.37 & 0.63 & 1.0 & 11.8 \\
\hline
\end{tabular}

The two-factor solution accounted for $37 \%$ of the variance, with the PI factor explaining $18 \%$ and the GA factor $19 \%$ of the variance. The inter-factor correlation was .35. Interestingly, this factorial solution mimics the two-factor solution expected and postulated in the literature (e.g., 8), with the highest loading of each item saturated in the theoretically correct factor.

Items Q2, Q6, Q9 and Q13 registered low loadings for the sample size (<.50) and some also showed cross-loadings with complexity and/or CL ratio values above those recommended $(35,36)$. Despite an acceptable primary loading, item Q5 showed inadequate complexity and CL ratio, evidencing cross-loading. An average EFA with different oblique rotation models was performed to ensure elimination decision. Visual analysis of loadings distribution suggested an absence of major fluctuations (see Figure 2). Although visually adequate, the ratio between loadings in item Q5 is still below the recommended (<.03; 36 ).

Furthermore, two Polytomous Item Response Theory analysis using generalized partial credit model - one for each factor - were performed (see Table 2). Results showed that the five aforementioned items reached discrimination values below the acceptable ( $\geq .70 ; 37)$, suggesting that they are not good at discriminating the latent trait and, therefore, supporting their removal. 
Table 2 Results of the PIRT analysis using Generalized Partial Credit Model per factor

\begin{tabular}{lllllllll}
\hline & Item & $\mathrm{a}$ & $\mathrm{b} 1$ & $\mathrm{~b} 2$ & $\mathrm{~b} 3$ & $\mathrm{~b} 4$ & $\mathrm{~b} 5$ & $\mathrm{~b} 6$ \\
\hline $\mathrm{PI}$ & Q8 & 1.923 & -1.291 & 0.412 & 0.555 & 0.648 & 1.405 & 2.168 \\
\cline { 2 - 7 } & Q10 & 1.113 & -0.902 & 1.497 & 0.326 & 2.984 & 0.719 & 2.37 \\
\hline Q12 & 1.007 & -3.341 & -0.347 & 0.101 & 0.368 & 1.232 & 2.045 \\
\hline Q14 & 0.7 & -2.772 & -0.5 & -0.219 & 1.044 & 2.667 & 1.377 \\
\hline Q2 & 0.562 & -1.256 & 1.656 & 0.281 & 1.997 & 3.852 & 1.318 \\
\hline Q6 & 0.425 & -0.963 & 3.325 & -0.416 & 2 & 6.297 & -1.44 \\
\hline Q5 & 0.31 & -3.701 & -0.189 & -0.637 & 2.211 & 0.023 & 2.199 \\
\hline GA Q1 & 1.234 & -1.891 & -1.952 & -1.419 & -1.734 & -0.749 & 0.476 \\
\hline Q7 & 1.093 & -0.284 & 1.034 & 0.75 & 1.149 & 2.399 & 3.239 \\
\hline Q15 & 0.513 & 0.298 & 0.961 & -0.659 & 2.148 & 3.051 & 0.839 \\
\hline Q4 & 0.465 & -1.704 & 0.273 & 0.247 & -0.689 & 0.237 & 1.611 \\
\hline Q11 & 0.449 & -1.279 & 0.417 & 1.284 & -2 & 2.384 & 0.837 \\
\hline Q3 & 0.422 & -2.268 & -0.802 & 0.348 & 1.044 & 0.262 & 0.067 \\
\hline Q13 & 0.386 & -3.475 & 0.881 & 1.476 & 0.234 & 1.961 & 4.371 \\
\hline Q9 & 0.234 & -1.348 & 0.674 & 0.614 & 0.395 & 0.104 & 1.327 \\
\hline
\end{tabular}

Note: $\mathrm{a}=$ discrimination ability; PI=Perceived Infectability; GA=Germ Aversion.

A CFA with WLSMV was used to confirm the 10-items bifactorial structure obtained from the EFA. Results revealed an acceptable global adjustment, $\chi 2(34)=$ 46.68; $\mathrm{CFI}=.93 ; \mathrm{TLI}=.91 ; \mathrm{RMSEA}=.05, \mathrm{RMSEA} 90 \% \mathrm{Cl}[.00, .09] ; \mathrm{SRMR}=.07$. Moreover, all items reached high factor weights and appropriate individual reliabilities on latent variables (see Figure 3 ).

Several CFAs were also compared to verify the factor structure that best fits the data. Apart from the original factor structure, and considering the cultural proximity, structure models from two Spanish studies assessing the psychometric properties of the PVD were tested with our sample. All models are present in Table 3. 


\begin{tabular}{|c|c|c|c|c|c|c|c|c|}
\hline & Model 1 & $\begin{array}{l}\text { Model } 2.1 \\
\text { Original }\end{array}$ & $\begin{array}{l}\text { Model } 2.2 \\
\text { Spain1 }\end{array}$ & $\begin{array}{l}\text { Model } 2.3 \\
\text { Portugal }\end{array}$ & $\begin{array}{l}\text { Model } 3.1 \\
\text { Spain2 }\end{array}$ & $\begin{array}{l}\text { Model } 3.2 \\
\text { Portugal }\end{array}$ & $\begin{array}{l}\text { Model } \\
4.1 \\
\text { Spain2 }\end{array}$ & $\begin{array}{l}\text { Model } 4.2 \\
\text { Portugal }\end{array}$ \\
\hline & $\begin{array}{l}\text { One Factor } \\
\text { PVD } \\
\text { (all items) }\end{array}$ & $\begin{array}{l}\text { Two } \\
\text { Factors } \\
\text { PI \& GA } \\
\text { (all items) }\end{array}$ & $\begin{array}{l}\text { Two } \\
\text { Factors } \\
\text { PI \& GA } \\
\text { (w/o } \\
\text { reverse } \\
\text { items) }\end{array}$ & $\begin{array}{l}\text { Two Factors } \\
\text { PI \& GA } \\
\text { (w/o items Q2, Q5, Q6, } \\
\text { Q9 and Q13) }\end{array}$ & $\begin{array}{l}\text { One Factor } \\
\text { PI } \\
\text { (all items) }\end{array}$ & $\begin{array}{l}\text { One Factor } \\
\text { PI } \\
\text { (w/o items Q2, } \\
\text { Q5 and Q6) }\end{array}$ & $\begin{array}{l}\text { One } \\
\text { Factor } \\
\text { GA } \\
\text { (all } \\
\text { items) }\end{array}$ & $\begin{array}{l}\text { One Factor } \\
\text { GA } \\
\text { (w/o items Q9 } \\
\text { and Q13) }\end{array}$ \\
\hline $\begin{array}{l}\chi 2 ; \\
p(d f)\end{array}$ & $237.68 ; p<.001(90)$ & $\begin{array}{l}\text { 147.43; } \\
p<.001(89)\end{array}$ & $\begin{array}{l}34.57 \\
\mathrm{p}=.12(26)\end{array}$ & $46.68 ; p=.07(34)$ & $\begin{array}{l}35.97 \\
p=.001(14)\end{array}$ & $11.57 ; p<.01(2)$ & $\begin{array}{l}17.51 \\
\mathrm{p}=.62(20)\end{array}$ & $\begin{array}{l}5.375 \\
p=.80(9)\end{array}$ \\
\hline CFI & .50 & .80 & .95 & .93 & .84 & .88 & 1.00 & 1.00 \\
\hline TLI & .42 & .77 & .93 & .91 & .76 & .63 & 1.02 & 1.04 \\
\hline $\begin{array}{l}\text { RMSEA } \\
(90 \% \mathrm{Cl})\end{array}$ & $.11(.09, .13)$ & $\begin{array}{l}.07(.05 \\
.09)\end{array}$ & $.05(0, .09)$ & $.05(0, .09)$ & $\begin{array}{l}.11(.07 \\
.15)\end{array}$ & $.19(.09, .30)$ & $0(0, .06)$ & $0(0, .06)$ \\
\hline SRMR & .12 & .09 & .06 & .07 & .08 & .07 & .04 & .03 \\
\hline $\begin{array}{l}\text { Loadings } \\
\text { Range }\end{array}$ & (.13 to .62$)$ & $\begin{array}{l}\mathrm{PI}(.28 \text { to } \\
.75) \\
\mathrm{GA}(.42 \text { to } \\
.70)\end{array}$ & $\begin{array}{l}\mathrm{PI}(.47 \text { to } \\
.83) \\
\mathrm{GA}(.41 \text { to } \\
.69)\end{array}$ & $\begin{array}{l}\mathrm{PI}(.63 \text { to } .75) \\
\mathrm{GA}(.52 \text { to } .70)\end{array}$ & (.41 to .78$)$ & (.61 to .79) & $\begin{array}{l}(.40 \text { to } \\
.69)\end{array}$ & (.55 to .67$)$ \\
\hline $\begin{array}{l}\text { Items } \\
\text { below } \\
0.5\end{array}$ & $\begin{array}{l}\text { Q3, Q5, Q6, Q8, Q9, } \\
\text { Q12, Q13, Q14 }\end{array}$ & $\begin{array}{l}\mathrm{PI}-\mathrm{Q} \text {, } \\
\mathrm{Q} 6 \\
\mathrm{GA}-\mathrm{Q} 3 \\
\mathrm{Q} 9\end{array}$ & $\begin{array}{l}\mathrm{PI}-\mathrm{Q6} \\
\mathrm{GA}-\mathrm{Q9}\end{array}$ & & Q5 & & Q9, Q13 & \\
\hline
\end{tabular}

Models 1, 2.1 and 3.1 obtained inadequate global and local adjustment values. Models 2.2 and 4.1, on the other hand, obtained acceptable values of global adjustment, but inappropriate local adjustment values. The remaining three models (i.e., 2.3, 3.2 and 4.2) reached acceptable values of global and local adjustments. Considering the conceptual framework and the original structure of the PVD, the bifactorial model obtained from the EFA (i.e., model 2.3) was adopted (see Additional file 1 for the original and final Portuguese version of the scale).

\section{Convergent and discriminant validity of PVD factors}

The Average Variance Extracted (AVE) and Composite Reliability (CR) values for both factors were as follows: $\mathrm{AVE}_{\mathrm{PI}}=.41, \mathrm{AVE}_{\mathrm{GA}}=.33, \mathrm{CR}_{\mathrm{PI}}>.79, \mathrm{CR}_{\mathrm{GA}}>.74$. While these AVE values are below those that are usually regarded as adequate (38), Fornell and Larcker (34) state that if the AVE values are less than .5, but the $\mathrm{CR}$ values are higher than .6, convergent validity of the construct is still considered adequate. Furthermore, both $\mathrm{CR}$ values are greater than .7, supporting the notion of an appropriate construct reliability. Thus, convergent validity of PVD factors was confirmed.

Furthermore, both AVE values were above the square of the correlation between the two factors (.12), indicating only $12.3 \%$ of common information between them and confirming the discriminant validity of the two-factor model (34).

\section{Convergent and discriminant validity of the scale}

Regarding convergent validity, as shown in Table 4, both PVD subscales significantly correlated with DPSS-R subscales, MOCl, MMPI-Hs and NEO-FFI Neuroticism, while DS-R total score, Core Disgust and Contamination-based Disgust subscales only correlated with GA. Furthermore, DPSS-R Disgust Propensity subscale and $\mathrm{MOCl}$ correlated more strongly with $\mathrm{GA}$, and $\mathrm{MMPI}-\mathrm{Hs}$ with $\mathrm{PI}$, as predicted. 


\begin{tabular}{|c|c|c|c|c|c|c|c|c|c|c|c|c|c|c|c|c|}
\hline Variables & 1 & 2 & 3 & 4 & 5 & 6 & 7 & 8 & 9 & 10 & 11 & 12 & 13 & 14 & 15 & 16 \\
\hline \multicolumn{17}{|l|}{ PVD } \\
\hline $\begin{array}{l}\text { 1. Perceived } \\
\text { Infectability }\end{array}$ & $(.82)$ & & & & & & & & & & & & & & & \\
\hline 2. Germ Aversion & $.27^{\star \star \star}$ & $(.82)$ & & & & & & & & & & & & & & \\
\hline \multicolumn{17}{|l|}{ DPSS-R } \\
\hline $\begin{array}{l}\text { 3. Disgust } \\
\text { Propensity }\end{array}$ & $.25^{\star \star}$ & $.34^{\star \star \star}$ & $(.85)$ & & & & & & & & & & & & & \\
\hline $\begin{array}{l}\text { 4. Disgust } \\
\text { Sensitivity }\end{array}$ & $.29^{\star \star \star}$ & $.22^{*}$ & $.50^{\star \star \star}$ & $(.87)$ & & & & & & & & & & & & \\
\hline \multicolumn{17}{|l|}{ DS-R } \\
\hline 5. Core Disgust & .04 & $.28^{\star \star \star}$ & $.31^{\star \star \star}$ & $.40^{\star \star \star}$ & $(.81)$ & & & & & & & & & & & \\
\hline $\begin{array}{l}\text { 6. Animal-reminder } \\
\text { Disgust }\end{array}$ & .02 & .11 & $.20^{*}$ & $.39^{\star \star \star}$ & $.68^{\star \star \star}$ & $(.82)$ & & & & & & & & & & \\
\hline $\begin{array}{l}\text { 7. Contamination- } \\
\text { based }\end{array}$ & .12 & $.41^{\star \star \star}$ & .16 & $.25^{\star *}$ & $.54^{\star \star \star}$ & $.37^{\star \star \star}$ & $\left(.58^{1}\right)$ & & & & & & & & & \\
\hline 8.Total & .00 & $.28^{\star * \star}$ & $.28^{\star \star \star}$ & $.43^{\star \star \star}$ & $.93^{\star \star \star}$ & $.86^{\star \star \star}$ & $.66^{\star \star \star}$ & $(.89)$ & & & & & & & & \\
\hline \multicolumn{17}{|l|}{$\mathrm{MOCl}$} \\
\hline 9.Total & $.39^{\star \star \star}$ & $.42^{\star \star \star}$ & $.43^{\star \star \star}$ & $.35^{\star \star \star}$ & $.18^{\star}$ & .12 & $.25^{\star \star}$ & $.20^{*}$ & $(.86)$ & & & & & & & \\
\hline \multicolumn{17}{|l|}{ SQ-R15 } \\
\hline 10. Total & .12 & .09 & $.38^{\star \star \star}$ & $.27^{\star \star}$ & $.30^{\star \star \star}$ & $.18^{\star}$ & .15 & $.27^{\star \star}$ & $.37^{\star \star \star}$ & $(.89)$ & & & & & & \\
\hline \multicolumn{17}{|l|}{ MMPI-Hs } \\
\hline 11. Total & $.32^{\star \star \star}$ & $.23^{\star \star}$ & $.41^{\star \star \star}$ & $.27^{\star *}$ & .13 & .14 & .10 & .15 & $.52^{\star \star \star}$ & $.29^{\star \star \star}$ & $(.94)$ & & & & & \\
\hline \multicolumn{17}{|l|}{ NEO-FFI } \\
\hline 12. Neuroticism & $.26^{\star *}$ & $.17^{\star}$ & $.32^{\star \star \star}$ & $.35^{\star \star \star}$ & $.20^{*}$ & .12 & .11 & $.18^{*}$ & $.54^{\star \star \star}$ & $.37^{\star \star \star}$ & $.57^{\star \star \star}$ & $(.88)$ & & & & \\
\hline 13. Extraversion & .15 & .11 & .10 & .01 & .06 & .11 & -.07 & .06 & $.24^{\star *}$ & -.08 & $.25^{\star \star}$ & $.45^{\star \star \star}$ & $(.84)$ & & & \\
\hline 14. Openness & .02 & .02 & .07 & $.17^{\star}$ & .07 & -.12 & -.07 & .10 & .11 & $-.23^{\star \star}$ & .14 & $.21^{*}$ & $.27^{\star \star}$ & $\left(.63^{2}\right)$ & & \\
\hline 15. Agreeableness & $.21^{\star \star}$ & .07 & .17 & .08 & .10 & .17 & -.08 & .10 & $.24^{*}$ & -.10 & $.27^{\star}$ & $.20^{*}$ & $.26^{\star *}$ & $.22^{*}$ & $(.80)$ & \\
\hline $\begin{array}{l}16 . \\
\text { Conscientiousness }\end{array}$ & .08 & $.24^{\star \star}$ & .00 & .06 & .04 & .11 & .09 & .09 & .05 & -.08 & .14 & $.25^{\star \star}$ & $.19^{*}$ & .09 & .14 & $(.89$ \\
\hline
\end{tabular}

Evidence for discriminant validity was also found as DS-R Animal-reminder Disgust, SQ-R15, and NEO-FFI Extraversion and Openness subscales did not significantly correlate with PVD factors. Likewise, NEO-FFI Agreeableness and Conscientiousness subscales showed low correlations with PI and GA, respectively.

\section{Reliability}

Both factors showed good levels of internal consistency (41), Ordinal Cronbach's $\mathrm{a}_{\mathrm{PI}}=.82, \mathrm{G} 6(\mathrm{smc})_{\mathrm{PI}}=.81$, Median $\mathrm{r}_{\mathrm{PI}}=.54$, Ordinal Cronbach's $\mathrm{a}_{\mathrm{GA}}=.82$, $\mathrm{G} 6(\mathrm{smc})_{\mathrm{GA}}=.80$, Median $\mathrm{r}_{\mathrm{GA}}=.45$.

\section{Discussion}

The present study explored the psychometric properties of the PVD with a nonclinical sample of the Portuguese population. Results support the bifactorial structure proposed by several authors (e.g., 39,42), including Duncan and colleagues, which measures two conceptually distinct factors modestly intercorrelated: Perceived Infectability and Germ Aversion. Accordingly, PI seems to be more associated with rational appraisals, while GA reflects behavioral and emotional reactivity (8). 
Although the original scale was comprised of 15 items, five problematic items were identified and, consequently, removed. Further analysis confirmed that these items did not reflect the latent factor they were supposed to be measuring. Regarding items Q5 and Q13, their reverse wording, which makes them harder to comprehend, might have been precluding participants from fully understanding their contents and causing the respective problematic loadings. In fact, both items have also been removed in other validation studies (40,e.g., 43). Furthermore, while most GA items mention behaviors or stimuli that, although from a broad spectrum, are commonly associated with disease (e.g., sharing a water bottle, washing/dirty hands), Q9's content (i.e., wearing used clothes) appears to be the least directly disease-related item, which might explain the low loadings found. Likewise, despite sharing similar wording and content with the rest of the PI items, Q2 and Q6 still reached inadequate loadings. As the remaining items adequately measure the construct, both items were removed. Finally, another possible explanation is that the problematic loadings of all these items, from a conceptual point-of-view, may reflect cultural differences related to the prevalence of infectious diseases in different locations (8).

Thus, the aforementioned exclusion led to a stronger scale structure, when compared to various other models, with adequate goodness-of-fit indices, evidence for convergent and discriminant validity and good internal consistency levels for both factors. In particular, the GA factor obtained a reliability score higher than the one commonly found in the literature (e.g., 8, 43).

Evidence for convergent validity of the scale was also found. First, both DPSS-R subscales positively correlated with PVD factors, with DPSS-R Disgust Sensitivity subscale correlating more strongly with PI, and DPSS-R Disgust Propensity subscale with GA. In fact, disgust propensity refers to how easily people respond with disgust and is more associated with avoidant action tendencies to repugnant materials, whereas disgust sensitivity is concerned with how unpleasant the experience of disgust really is and is linked with more general emotional sensitivity $(44,45)$. Accordingly, if we look at the items from both PVD subscales, GA items involve actions (e.g., sharing a water bottle), while PI items include thoughts/beliefs about developing an infectious disease (e.g., higher susceptibility). Thus, these results add to the literature by suggesting that PI is more strongly related to disgust sensitivity and confirm the predicted link between GA and disgust propensity. Likewise, as a measure of disgust propensity, DS-R was expected to correlate with both PVD factors, albeit more strongly with GA. However, only a positive and significant correlation was found for the latter. This correlation was found for the total score, and both Core Disgust and Contamination-based Disgust subscales (both related to threat of infection; 46). These results provide further evidence of the link between disgust propensity and GA and, more notably, highlight the conceptual distinction between both PVD factors.

A positive and significant correlation between both PVD factors and MMPI-Hs, MOCl and NEO-FFI Neuroticism was also found, as predicted, further corroborating the convergent validity of the scale. In particular, MMPI-Hs was found to correlate more strongly with PI, not surprisingly given that both constructs measure beliefs about disease. Conversely, GA correlated more strongly with both MOCl, as expected, and NEO-FFI Neuroticism. Interestingly, positive correlations between $\mathrm{MOCl}$ and both DS-R Core Disgust and Contamination-based Disgust subscales (i.e., disgust propensity measures correlated with GA) were also found. Taken together, these findings suggest that obsessive-compulsive symptoms may be tied to GA through disgust propensity, which is in line with a recent study that suggested that GA plays a mediator role between disgust propensity and contamination-based OCD (47). Thus, our results corroborate the connection between these constructs even further. Finally, the positive correlation found between NEO-FFI Neuroticism and both PVD factors supports the findings of Duncan and collaborators (8), but contradicts those of Díaz and colleagues (40). Since neuroticism is characterized by a tendency to experience negative emotions and psychological distress (21), the stronger correlation found for GA might be explained by this factor's latent association with emotional reactivity.

Regarding the discriminant validity of the scale, DS-R Animal-reminder Disgust, SQ-R15, and NEO-FFI Extraversion and Openness subscales were not correlated with PVD factors, as predicted. Likewise, low correlations were found between PVD factors and NEO-FFI Agreeableness and Conscientiousness. Thus, these results provide further evidence of the PVD's discriminant validity.

Despite the encouraging results, this study has some limitations, like the use of a nonclinical university sample and the high proportion of women, which limits the generalizability of the findings. Furthermore, cultural differences are influenced by the prevalence of infectious diseases and, thus, might be implicated in one's perceived vulnerability to disease (8). Consequently, our results might only be representative of regions with similar geographies or climates. Future research should use a more diverse and gender-balanced sample to further extend these results. Using a clinical sample would also be valuable to explore how one's own health (physical or psychological) might influence perceived vulnerability to disease. Lastly, temporal stability analysis should also be explored.

\section{Conclusion}

Individual differences in perceived vulnerability to infectious diseases are involved in disease avoidance responses and have implications for various psychological outcomes. This research aimed to analyze the psychometric properties of the PVD for the Portuguese population. Overall, the 10-items bifactorial solution of the European-Portuguese PVD appears to be a reliable and valid measure of one's perceived vulnerability to disease. Thus, this instrument may offer a significant contribute to study social cognition and behavioral processes related to disease avoidance.

\section{Abbreviations}

AVE: Average Variance Extracted

BIS: Behavioral Immune System

CFA: Confirmatory Factor Analysis

CFI: Comparative Fit Index

CR: Composite Reliability 
DPSS-R: Disgust Propensity and Sensitivity Scale-Revised

DS-R: Disgust Scale-Revised

EFA: Exploratory Factor Analysis

GA: Germ Aversion

KMO: Kaiser-Meyer-Olkin Measure of Sampling Adequacy

MMPI-2 Hs: Minnesota Multiphasic Personality Inventory-2 Hypochondria subscale

MOCl: Maudsley Obsessive Compulsive Inventory

NEO-FFI: NEO-Five Factor Inventory

PI: Perceived Infectability

PVD: Perceived Vulnerability to Disease Questionnaire

RMSEA: Root Mean Square Error of Approximation

SPQ-R15: Spider Phobia Questionnaire-Revised

SRMR: Standardized Root-Mean-Residual

TLI: Tucker-Lewis Index

ULS: Unweighted Least-squares Estimator

WLSMV: Weighted Least-square-mean and Variance Adjusted Estimator

2: Chi-square

\section{Declarations}

\section{Ethics approval and consent to participate}

The study was approved by the Ethics Committee of the University of Aveiro. Participation in the study was voluntary and anonymous. The informed consent was obtained from all subjects. All methods of the study were carried out in accordance with the Declaration of Helsinki and the standards of the American Psychological Association.

\section{Consent for publication}

Not applicable.

\section{Availability of data and materials}

The dataset and additional materials supporting the conclusions of this article are available in the Open Science Framework repository, through a view-only link at https://osf.io/hb48s/?view_only=c6bf2dfabd784a89977151c46581c62a.

\section{Competing interests}

The authors have no relevant financial or non-financial interests to disclose.

\section{Funding}

This research was supported by the Portuguese Foundation for Science and Technology [Grant numbers SFRH/BD/85376/2012 and SFRH/BD/137993/2018]. The funders had no role in study design, data collection and analysis, decision to publish, or preparation of the manuscript.

\section{Authors' contributions}

Jacqueline Ferreira: Conceptualization, Methodology, Software, Investigation, Writing - Review \& Editing

Ana C. Magalhães: Formal analysis, Writing - Original Draft, Writing - Review \& Editing

Pedro Bem-Haja: Software, Formal analysis, Writing - Review \& Editing

Laura Alho: Conceptualization; Methodology

Carlos F. Silva: Supervision

Page 9/12 
Sandra C. Soares: Conceptualization, Writing - Review \& Editing, Supervision

\section{Acknowledgements}

The authors would like to thank the participants of the study.

\section{References}

1. Murray DR, Prokosch ML, Airington Z. PsychoBehavioroimmunology: Connecting the behavioral immune system to its physiological foundations. Front Psychol. 2019;10:1-7.

2. Schaller M. The behavioural immune system and the psychology of human sociality. Philos Trans R Soc B Biol Sci. 2011;366(1583):3418-26.

3. Ackerman JM, Hill SE, Murray DR. The behavioral immune system: Current concerns and future directions. Soc Personal Psychol Compass. 2018;12(2):57-70.

4. Murray DR, Schaller M. The behavioral immune system: Implications for social cognition, social interaction, and social influence. In: Advances in Experimental Social Psychology. Academic Press; 2016. p. 75-129.

5. Schaller M, Park JH. The behavioral immune system (and why it matters). Curr Dir Psychol Sci. 2011;20(2):99-103.

6. Miller SL, Maner JK. Overperceiving disease cues: The basic cognition of the behavioral immune system. J Pers Soc Psychol. 2012;102(6):1198-213.

7. Mortensen CR, Becker DV, Ackerman JM, Neuberg SL, Kenrick DT. Infection breeds reticence: The effects of disease salience on self-perceptions of personality and behavioral avoidance tendencies. Psychol Sci. 2010;21(3):440-7.

8. Duncan LA, Schaller M, Park JH. Perceived vulnerability to disease: Development and validation of a 15-item self-report instrument. Pers Individ Dif. 2009;47(6):541-6.

9. Park JH, Faulkner J, Schaller M. Evolved disease-avoidance processes and contemporary anti-social behavior: Prejudicial attitudes and avoidance of people with physical disabilities. J Nonverbal Behav. 2003;27(2):65-87.

10. Park JH, Schaller M, Crandall CS. Pathogen-avoidance mechanisms and the stigmatization of obese people. Evol Hum Behav. 2007;28(6):410-4.

11. Duncan LA, Schaller M. Prejudicial attitudes toward older adults may be exaggerated when people feel vulnerable to infectious disease: Evidence and implications. Anal Soc Issues Public Policy. 2009;9(1):97-115.

12. Navarrete CD, Fessler DM, Eng SJ. Elevated ethnocentrism in the first trimester of pregnancy. Evol Hum Behav. 2007;28(1):60-5.

13. Faulkner J, Schaller M, Park JH, Duncan LA. Evolved disease-avoidance mechanisms and contemporary xenophobic attitudes. Gr Process Intergr Relations. 2004;7(4):333-53.

14. Makhanova A, Shepherd MA. Behavioral immune system linked to responses to the threat of COVID-19. Pers Individ Dif. 2020;167:110221.

15. Stangier U, Kananian S, Schüller J. Perceived vulnerability to disease, knowledge about COVID-19, and changes in preventive behavior during lockdown in a German convenience sample. Curr Psychol. 2021.

16. Ferreira J, Bem-Haja P, Alho L, Soares SC. Subjective experience of disgust - Portuguese Version of Disgust Propensity and Sensitivity Scale - Revised. Eur J Heal Psychol. 2021;28(1):13-21.

17. Ferreira-Santos F, Martins E, Sousa P, Mauro C. Escala de Sensibilidade ao Nojo-Revista, versões Português de Portugal (DS-R-pt) e Português do Brasil (DS-R-br). 2011.

18. Nogueira V, Macedo A, Pereira AT, Marques M, Soares MJ, Valente J, et al. P-815 - Psychometric properties and factor structure of the portuguese version of the Maudsley Obsessional-Compulsive Inventory. Eur Psychiatry. 2012;27(1).

19. Silva, Soares, Esteves. In preparation.

20. Silva D, Novo R, Prazeres N, Pires R. Inventário Multifásico de Personalidade de Minnesota (Adultos): Versão experimental portuguesa do MMPI-2 [Minnesota Multiphasic Personality Inventory (Adults): Portuguese experimental version of MMPI-2]. Lisboa: Centro de Investigação em Psicologia e Faculdade de Psicologia da Universidade de Lisboa; 2006.

21. Barros AM. Os valores e o modelo dos cinco fatores da personalidade: Aplicação de dois instrumentos de medida a uma amostra de adultos trabalhadores. Universidade de Lisboa; 1997.

22. Gudmundsson E. Guidelines for translating and adapting psychological instruments. Nord Psychol. 2009;61(2):29-45.

23. R Core Team. R: A language and environment for statistical computing. Vienna, Austria: R Foundation for Statistical Computing; 2020.

24. Xie Y, Qiu Y. highr: Syntax Highlighting for R Source Code. In: R package version 09. 2021.

25. Chan C-H, Chan GCH, Leeper TJ, Becker J. rio: A Swiss-army knife for data file I/O. In: R package version 0527. 2021.

26. Revelle W. psych: Procedures for Personality and Psychological Research. In: R package version 219. Evanston, Illinois, USA: Northwestern University; 2021.

27. Bernaards CA, Jennrich RI. Gradient Projection Algorithms and Software for Arbitrary Rotation Criteria in Factor Analysis. Educ Psychol Meas. 2005;65:676-96.

28. Steiner MD, Grieder SG. EFAtools: An R package with fast and flexible implementations of exploratory factor analysis tools. J Open Source Softw. 2020;5(53):2521.

29. Wickham H, Bryan J. readxl: Read Excel Files. In: R package version 131. 2019.

30. Rosseel Y. lavaan: An R Package for Structural Equation Modeling. J Stat Softw. 2012;48(2):1-36.

Page $10 / 12$ 
31. Mardia K V. Measures of multivariate skewness and kurtosis with applications. Biometrika. 1970.

32. Jöreskog KG, Sörbom D. LISREL 8: User's reference guide. Scientific Software International; 1996.

33. Marôco J. Analysis of structural equations: Theoretical fundamentals, software \& applications. 2nd ed. Pêro Pinheiro, Portugal: REPORTNUMBER; 2014. $1-400 \mathrm{p}$.

34. Fornell C, Larcker DF. Evaluating structural equation models with unobservable variables and measurement error. J Mark Res. 1981;18(1):39-50.

35. Hair JF, Black WC, Babin BJ, Anderson RE. Multivariate data analysis: A global perspective. 7th ed. Upper Saddle River, New Jersey: Prentice Hall; 2009.

36. Matsunaga M. How to factor-analysis your data: Do's, don'ts, and how-to's. Int J Psychol Res. 2010;3(1):97-110.

37. Embretson SE, Reise SP. Item response theory for psychologists. Matawah, NJ: Erlbaum Publishers; 2000.

38. Hair JF, Anderson R, Tatham R, Black W. Multivariate data analysis. 5th ed. Technometrics. Upper Saddle River, New Jersey: Prentice Hall; 1998.

39. Magallares A, Fuster-Ruiz MJ, Morales JF. Psychometric properties and criterion validity of the Perceived Vulnerability to Disease Scale (PVD) in the Spanish population. Int J Soc Psychol. 2017;32(1):164-95.

40. Díaz A, Soriano JF, Beleña Á. Perceived Vulnerability to Disease Questionnaire: Factor structure, psychometric properties and gender differences. Pers Individ Dif. 2016;101:42-9.

41. Zumbo BD, Gadermann AM, Zeisser C. Ordinal versions of coefficients alpha and theta for likert rating scales. J Mod Appl Stat Methods. 2007;6(1):21-9.

42. Murray DR, Jones DN, Schaller M. Perceived threat of infectious disease and its implications for sexual attitudes. Pers Individ Dif. 2013;54(1):103-8.

43. Magallares A, Jauregui-Lobera I, Carbonero-Carreño R, Ruiz-Prieto I, Bolaños-Ríos P, Cano-Escoriaza A. Perceived vulnerability to disease and antifat attitudes in a sample of children and teenagers. Eat Weight Disord. 2015;20(4):483-9.

44. van Overveld M, Jong PJ d., Peters ML. The Disgust Propensity and Sensitivity Scale - Revised: Its predictive value for avoidance behavior. Pers Individ Dif. 2010;49(7):706-11.

45. Goetz AR, Lee HJ, Cougle JR, Turkel JE. Disgust propensity and sensitivity: Differential relationships with obsessive-compulsive symptoms and behavioral approach task performance. J Obsessive Compuls Relat Disord. 2013;2(4):412-9.

46. Olatunji BO, Williams NL, Tolin DF, Abramowitz JS, Sawchuk CN, Lohr JM, et al. The Disgust Scale: Item analysis, factor structure, and suggestions for refinement. Psychol Assess. 2007;19(3):281-97.

47. Brady RE, Badour CL, Arega EA, Levy JJ, Adams TG. Evaluating the mediating effects of perceived vulnerability to disease in the relation between disgust and contamination-based OCD. J Anxiety Disord. 2021;79:102384.

\section{Figures}

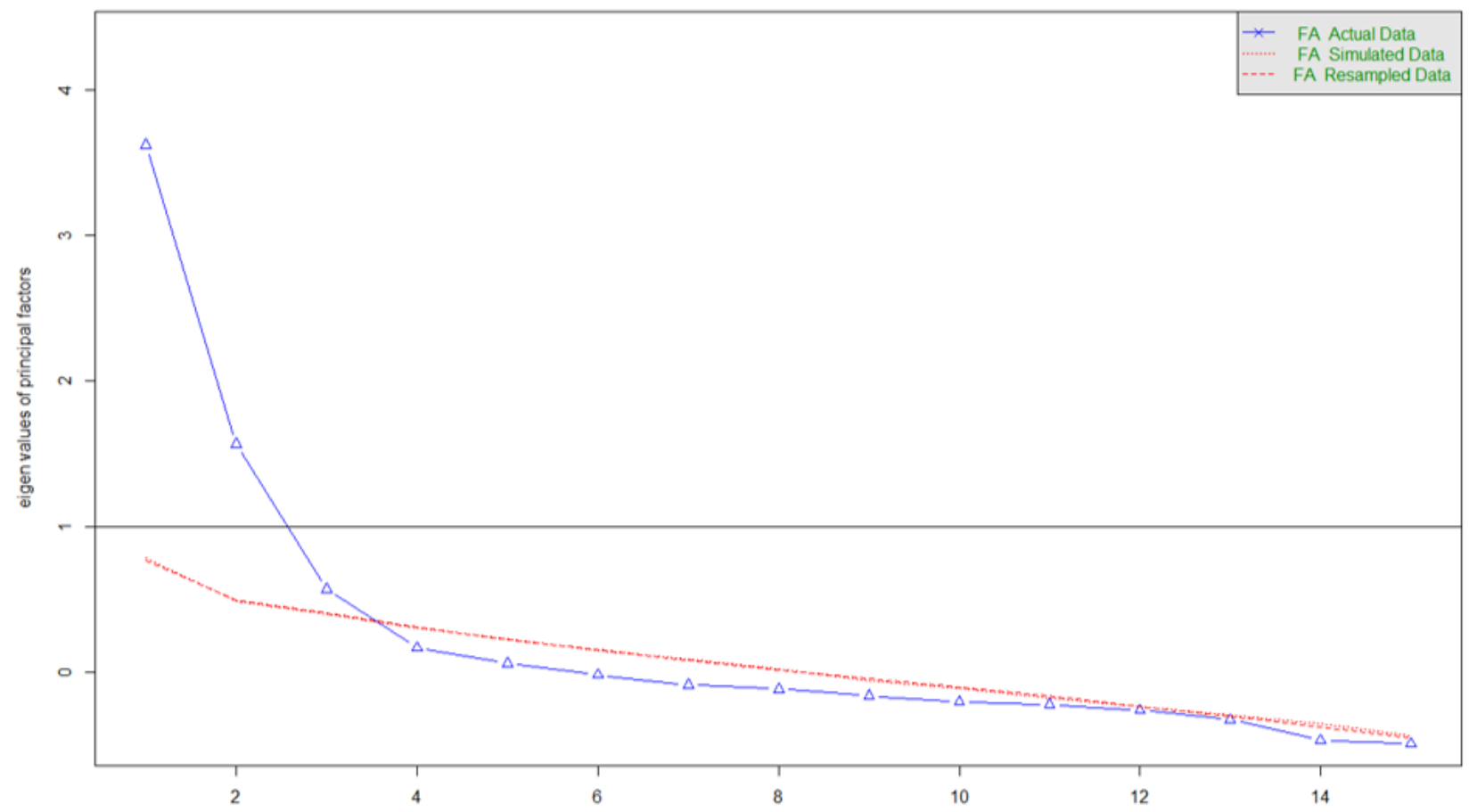

Figure 1

Parallel analysis scree plot with ULS estimator. 


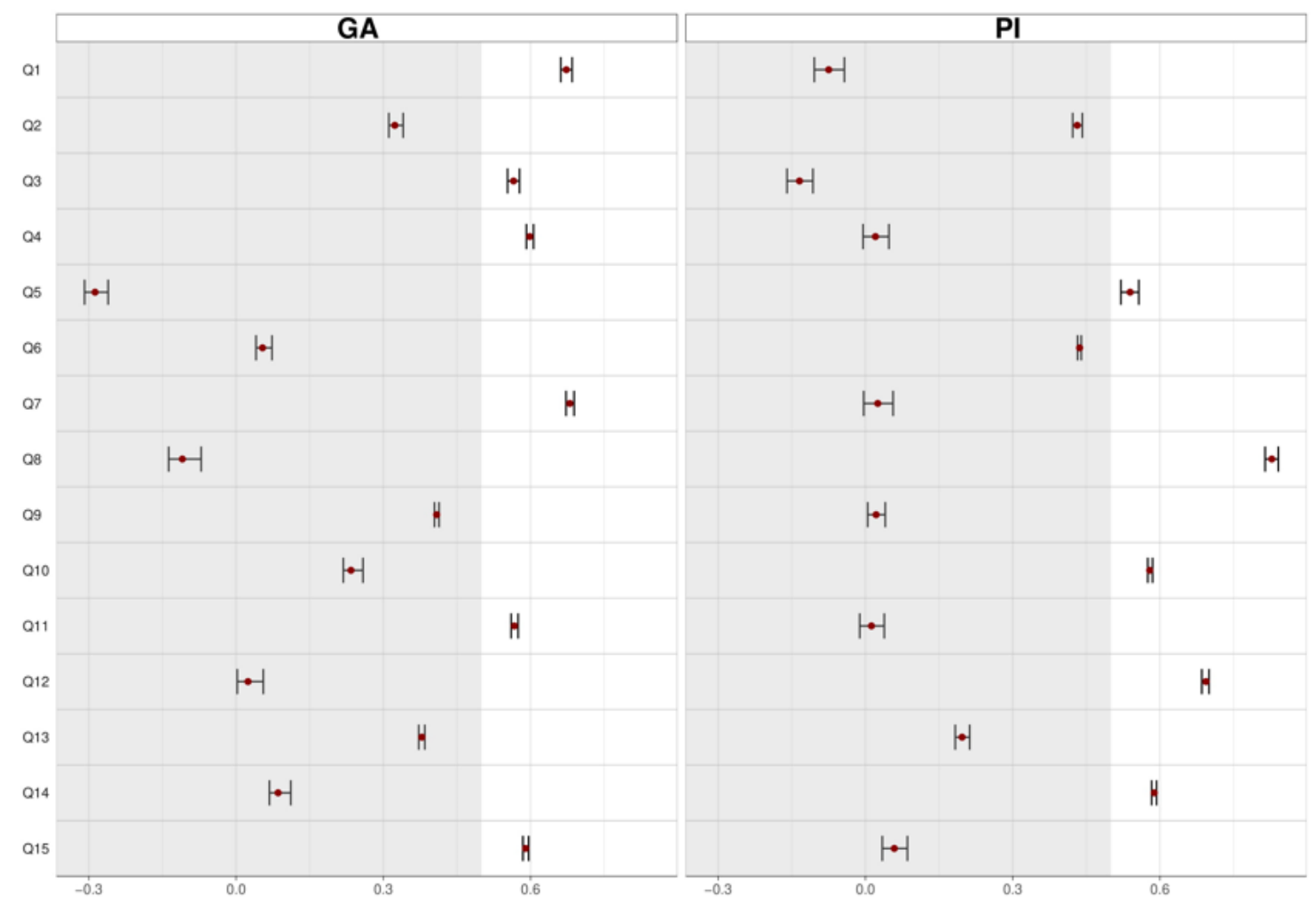

Figure 2

Average, maximum, and minimum loadings for each item per factor. Note: GA = Germ Aversion; PI = Perceived Infectability.

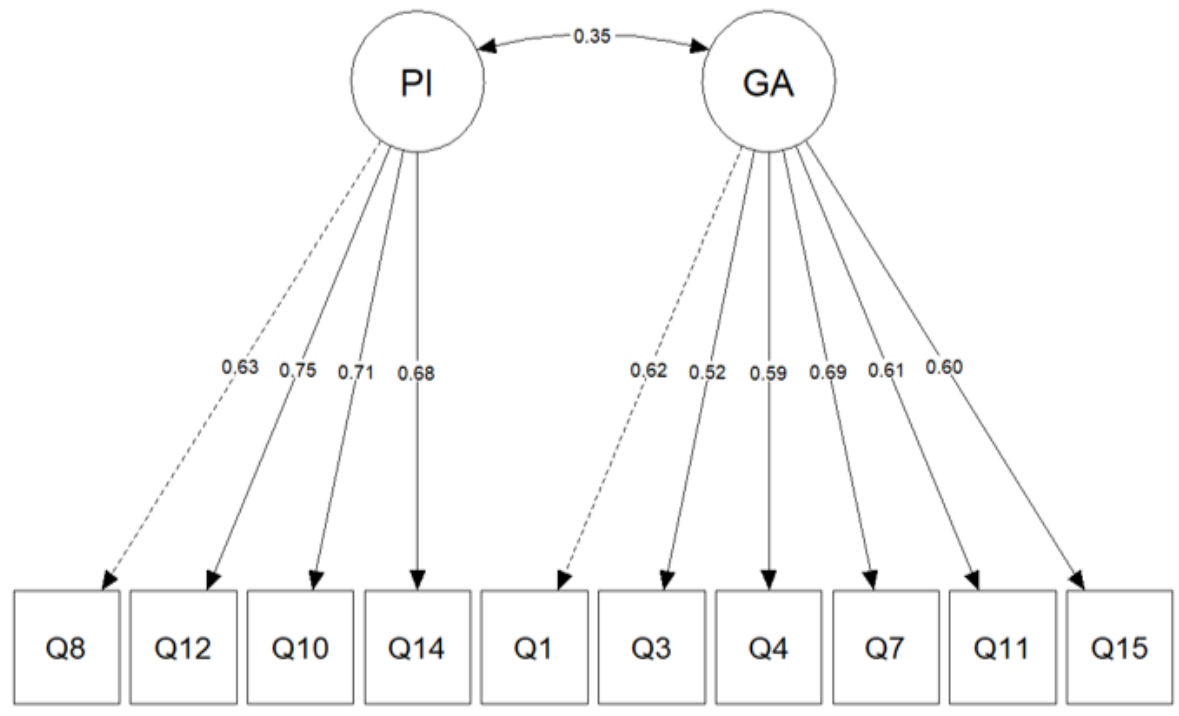

Figure 3

Diagram of two-factor structure (10 items) obtained using CFA with WLSMV estimator. Note: PI = Perceived Infectability; GA = Germ Aversion.

\section{Supplementary Files}

This is a list of supplementary files associated with this preprint. Click to download.

- SupplementaryMaterialOriginalandPortuguesePVDitems.docx 